\title{
A Terapia Ocupacional em um processo de capacitação sobre vigilância do desenvolvimento infantil na atenção básica em saúde
}

\author{
Patrícia Carla de Souza Della Barba, Vanessa de Melo Barros, Érika de Aquino Marques, \\ Aline Zacchi Farias, Bárbara Aniceto, Evellin Eri Miyamoto
}

Universidade Federal de São Carlos - UFSCar, São Carlos, SP, Brasil.

\begin{abstract}
Resumo: O currículo do curso de Terapia Ocupacional da Universidade Federal de São Carlos (UFSCar) pressupõe que a inserção do estudante no cenário da atenção básica em saúde traz benefícios para a aprendizagem do estudante e para a melhoria da qualidade da atenção. As experiências aqui descritas foram vivenciadas por alunas de graduação em virtude da atividade de extensão denominada "Formação de alunos de graduação em Terapia Ocupacional e de agentes comunitários de saúde para a promoção de ações de vigilância do desenvolvimento infantil na atenção primária à saúde", com objetivo principal de fomentar ações voltadas ao desenvolvimento infantil na atenção primária com Equipes de Saúde da Família, por meio da formação de alunos do curso de Terapia Ocupacional. O material adotado foi a cartilha "Toda hora é hora de cuidar". São descritas neste relato a segunda (capacitação dos agentes comunitários de saúde) e a terceira (replicação da capacitação com as famílias usuárias das Unidades de Saúde da Família) etapas da atividade de extensão a partir de relatórios de campo das alunas participantes. As capacitações ocorreram em duas Unidades de Saúde da Família. Verificou-se a potência de promover ações de vigilância do desenvolvimento infantil a partir das capacitações oferecidas aos agentes comunitários. Conclui-se que o processo de ensino-aprendizagem no contexto da atenção básica em saúde contribuiu para a interação dos estudantes com os usuários do serviço e com as equipes, o que facilitou a compreensão sobre o Sistema Único de Saúde e potencializou as discussões sobre a atuação da Terapia Ocupacional na comunidade para além das ações de reabilitação.
\end{abstract}

Palavras-chave: Terapia Ocupacional, Vigilância, Desenvolvimento Infantil.

\section{Occupational Therapy in a process of training on child development's surveillance in primary care health}

\begin{abstract}
The curriculum of UFSCar's occupational therapy graduation assumes that the student's inclusion in the venue of primary care brings benefits both to student learning and improvements in the quality of care given. Set this, the participation of students in communities' activities is encouraged. The experiments described in this paper were experienced by undergraduate students on the in-field activity called "Training graduate students in occupational therapy and community health agents to promote child development surveillance activities in primary health care", with the main goal of promoting actions aimed at child's development in primary care at the Families' Health Teams in São Carlos, through the training of students of occupational therapy. The material used was the booklet "Every Time is Caring Time", containing nine themes: care of the pregnant woman, bond, affection, vaccination schedule, child development, nutrition, hygiene, disease's precautions, accidents' prevention and the children's rights. This report describes the second (training of Community Health Workers) and third (replication of training at the user families of the Family Health Units) extension activity steps from field reports of students enrolled in
\end{abstract}

Autor para correspondência: Vanessa de Melo Barros, Laboratório de Atividade e Desenvolvimento, Departamento de Terapia Ocupacional, Universidade Federal de São Carlos, Rodovia Washington Luís, Km 235, s/n, Jardim Guanabara, CEP 13565-905, São Carlos, SP, Brasil, e-mail: vanessaufscar10@yahoo.com

Recebido em Out. 19, 2015; $1^{\text {a }}$ Revisão em Fev. 18, 2016; $2^{\text {a }}$ Revisão em Maio 12, 2016; $3^{\text {a }}$ Revisão em Set. 26, 2016 ; Aceito em Out. 4 , 2016. 
the project. The training took place in the neighborhood of Jd. São Carlos and Maria Stella Fagá. The potential of promoting child's development activities through Communities Agents was also verified. Concluding that using Primary Health Care context to teach and learn was extremely efficient in the scope of understanding the NHS and comprehending the role of an Occupational Therapist in the community, going beyond the rehabilitation actions.

Keywords: Occupational Therapy, Surveillance, Child Development.

\section{Introdução}

\subsection{Aproximação do aluno de graduação com equipes de saúde da atenção básica}

O curso de Terapia Ocupacional da Universidade Federal de São Carlos (UFSCar) teve seu início em 1978, e, desde então, algumas adequaçôes curriculares foram realizadas. Em 2008, houve uma grande reformulaçáo, com o processo educacional enfocando o pensar crítico-reflexivo e possibilitando aos discentes um espaço de participação em contextos ou cenários de investigação, indagação, reflexão e ação (DELLA BARBA et al., 2012).

Esse currículo, ao adotar uma abordagem socioconstrutivista da educação, estimula a capacidade de pensar, refletir, aprender a aprender, relacionar o conhecimento com dados da experiência diária, estabelecer relação entre teoria e prática, fundamentando criticamente com base em fatos do cotidiano e proporcionando aos sujeitos da aprendizagem a construção do seu próprio conhecimento, a qual acontece na interaçấo com o meio físico e social, com o simbolismo humano e com o mundo das relaçóes sociais (DELLA BARBA et al., 2012).

Nesse sentido, os processos metodológicos e pedagógicos promovem a diversificação de cenários de ensino-aprendizagem, e a formação permite a ampla participação dos estudantes e dos professores na rede de serviços do município, como a de serviços de saúde. Dessa forma, cumpre-se uma das missóes fundamentais na formação de profissionais de saúde, a contribuição para a construção de novas práticas e de desempenhos com impacto social (UNIVERSIDADE..., 2008).

No currículo do curso de Terapia Ocupacional da UFSCar, pressupóe-se que a inserção do estudante no cenário da atenção básica, especialmente nas ações de promoção da saúde, pode trazer benefícios para a aprendizagem do estudante e para a melhoria da qualidade da atenção.

O princípio de indissociabilidade entre as atividades de ensino, pesquisa e extensão na UFSCar é concretizado por meio de programas de extensão que estimulam e integram alunos, professores, e servidores técnico-administrativos de diferentes áreas de conhecimento no desenvolvimento de projetos institucionais multi e interdisciplinares (UNIVERSIDADE..., 2010). O curso de graduação em Terapia Ocupacional tem tido tradicionalmente forte inserção extensionista, em consonância com seu projeto pedagógico. Nesse sentido, os estudantes são incentivados a participar de atividades de extensão comunitária e a ter contato com serviços, entre eles a atenção básica à saúde.

\subsection{A atividade de extensão na Terapia Ocupacional como provedora da vigilância do desenvolvimento infantil}

As experiências descritas no presente trabalho foram vivenciadas por alunas de graduação em virtude da atividade de extensão denominada "Formaçáo de alunos de graduação em Terapia Ocupacional e de agentes comunitários de saúde para a promoção de açôes de vigilância do desenvolvimento infantil na atençáo primária à saúde", oferecida desde 2011 com a supervisão da Profa. Dra. Patrícia Della Barba, do Departamento de Terapia Ocupacional, com objetivo principal de fomentar açóes voltadas ao desenvolvimento infantil na atenção primária com Equipes de Saúde da Família do município de São Carlos.

Partindo da premissa da possibilidade de se investir na vigilância do desenvolvimento infantil e no cuidado integral à criança no cenário da atenção primária à saúde, valorizando o acompanhamento da família desde a gestação até os três primeiros anos de vida e a forte aproximação entre o profissional de saúde e as famílias usuárias dos serviços, o projeto de extensão se concretizou.

Quando nos referimos à criança, a mãe geralmente assume o papel de principal cuidadora no âmbito familiar, tendo em vista que a própria criança sente na figura materna uma proteção ímpar (BECK; LOPES, 2007).

Segundo Helen Bee (2003), o ambiente familiar da criança também afeta sua trajetória. Se esse ambiente for enriquecido com objetos estimulantes, somada 
a uma boa orientação dos pais e/ou cuidadores, o desenvolvimento dessa criança será beneficiado.

Porém, se esse ambiente for desprovido de estímulos e houver falta de conhecimento dos cuidadores principais diante de determinadas situaçóes do dia a dia, ele se torna insustentável para o desenvolvimento básico (BEE, 2003).

De acordo com Lordelo, Fonseca e Araujo (2000, p. 74):

A diversidade de ambientes nos quais a criança se desenvolve, com a crescente importância das creches e pré-escolas como contextos modernos de desenvolvimento, estabelece desafios para a compreensão dos mecanismos de ajuste dos sujeitos participantes - crianças e adultos, a esses contextos. A investigação do ambiente doméstico, particularmente na sua dimensão social, pode indicar os elementos relevantes para a comparação dos diferentes ambientes em termos das suas potencialidades e limitações.

Sendo assim, a responsabilidade com o cuidado e o apoio amoroso da família possui impacto sobre o padrão de apego da criança, sobre sua auto aceitação e sobre a motivação para lidar com situaçóes adversas e explorar o novo (BEE, 2003).

O material adotado pela atividade de extensão aborda a vigilância do desenvolvimento da criança, principalmente por seus familiares, é denominado "Toda hora é hora de cuidar" e é composto por cartilha e manual de apoio à equipe. Sua elaboração é resultado das parcerias entre a Secretaria Municipal da Saúde de São Paulo, o Fundo das Naçóes Unidas para a Infância (UNICEF) e a Associação Comunitária Monte Azul, além do apoio de instituiçóes como a Escola de Enfermagem da Universidade de Sáo Paulo (USP) e a Pastoral da Criança, com utilização pelo Programa Saúde da Família da cidade de São Paulo em 2003 (CHIESA; BATISTA, 2003).

São trabalhados nove temas pela cartilha: cuidado com a gestante, vínculo-afeto, calendário de vacinação, desenvolvimento infantil, alimentação, higiene, cuidado com as doenças, cuidado com acidentes e direitos das crianças. A partir da necessidade de utilizar uma linguagem acessível não somente para o profissional de saúde, mas também para as famílias da região, a atividade de extensão utilizou estratégias que se baseiam nas oficinas problematizadoras. Estas, segundo Chiesa e Batista (2003), permitem a exploração do conhecimento prévio dos participantes, o desenvolvimento do raciocínio clínico e epidemiológico, a formulação de hipóteses, a busca e análise crítica do conhecimento necessário para melhor explicar o problema e a formulação de planos de cuidado para situaçóes individuais e coletivas.

As atividades de capacitação ocorreram em três fases. A primeira, que foi realizada no Laboratório de Atividade e Desenvolvimento do Departamento de Terapia Ocupacional da UFSCar, contou com a capacitação prévia dos graduandos em Terapia Ocupacional pela equipe de trabalho. $\mathrm{Na}$ segunda, ocorreu a capacitação dos agentes comunitários de saúde (ACS) das Unidades de Saúde da Família (USF) pelos próprios estudantes. Esses ACS e os graduandos capacitados replicaram o conteúdo da cartilha com as famílias usuárias das USF - terceira e última etapa do projeto de extensão.

As duas últimas etapas foram desenvolvidas no contexto da atenção básica, pensando que a aproximação com o conceito de territorialização é um dos pressupostos básicos para atuação dos profissionais das USF, visando a uma compreensão melhor do seu campo de trabalho (BRASIL, 2012).

Nesse sentido, o território pode referir-se aos limites das áreas de atuação do serviço, ao reconhecimento do ambiente e da população e sua dinâmica social, e ao estabelecimento de relaçóes com outros serviços oferecidos naquela determinada área (PEREIRA, 2006).

No município de Sáo Carlos, incorporando também os distritos de Água Vermelha e Santa Eudóxia, os territórios foram divididos por meio das Administraçóes Regionais de Saúde (ARES), as quais têm como função organizar as USF na área de sua abrangência, bem como proporcionar a existência do cuidado integral às necessidades de saúde dos moradores pertencentes ao território. Atualmente, são cinco ARES existentes no município: ARES 1, Aracy; ARES 2, Vila Isabel; ARES 3, Redenção; ARES 4, São José; ARES 5, Santa Felícia.

As experiências vivenciadas e compartilhadas ocorreram na USF Jardim São Carlos e na USF Maria Stella Fagá, pertencentes, respectivamente, ao ARES Redenção e ao ARES São José.

\section{Método}

O presente estudo caracteriza-se como um relato de experiência, cujo objetivo é descrever as observaçóes e as reflexóes de alunas do curso de Terapia Ocupacional após capacitaçóes de ACS e famílias usuárias de USF.

Trata-se de um estudo de natureza qualitativa e descritiva, elaborado a partir da criaçáo de um diário de campo, com observaçóes de todo o 
processo de capacitação, no período de outubro a dezembro de 2014. Os registros foram elaborados após os encontros de capacitaçóes e discutidos em reuniôes realizadas pelas alunas e orientadora após o término da pesquisa.

Segundo Godoy (1995), os estudos denominados qualitativos têm como preocupação fundamental o estudo e a análise do mundo empírico em seu ambiente natural. Nessa abordagem, valoriza-se o contato direto e prolongado do pesquisador com o ambiente e a situaçáo que está sendo estudada. $O$ pesquisador deve aprender a usar sua própria pessoa como o instrumento mais confiável de observação, seleção, análise e interpretação dos dados coletados.

Sendo assim, em específico, buscou-se promover um espaço dentro da USF onde os ACS pudessem estudar, dialogar e compreender melhor o desenvolvimento integral da criança e, assim, transmitir às famílias seus conhecimentos sobre o assunto. As USF citadas neste relato foram sugeridas pela Secretaria Municipal de Saúde do município e contatadas para a participação na pesquisa, mediante aceite e assinatura do Termo de Consentimento Livre e Esclarecido.

Nesse contexto, entende-se que o relato de experiência é uma ferramenta de pesquisa que busca apresentar uma reflexão sobre uma ação ou um conjunto de açóes relacionadas às vivências - neste caso, de alunas do curso de Terapia Ocupacional inseridas na prática profissional da atenção básica.

\section{Resultados e Discussão}

A análise dos dados evidenciou aspectos relevantes e pertinentes tanto para uma abordagem baseada em oficinas problematizadoras, em espaços de capacitação na atenção básica, como a identificaçáo de lacunas no conhecimento de famílias sobre o desenvolvimento integral da criança, os quais serão descritos a seguir.

\subsection{Capacitação dos agentes comunitários de saúde (ACS)}

\subsubsection{USF Jardim São Carlos}

Na USF Jardim São Carlos, foram realizados três encontros a fim de propor conversas sobre os temas já citados da cartilha. Como material, foram utilizadas a própria cartilha, artigos científicos e materiais para a realização de dinâmicas.

Todos os ACS participaram da capacitação. Algumas faltas decorrentes da grande demanda de serviço da própria unidade não atrapalharam o processo de formação. As capacitaçóes ocorreram no período de trabalho, em um horário reservado para a reunião dos ACS.

As discussóes dos temas ocorreram em formato de roda de conversa, com apenas o tema relacionado ao desenvolvimento infantil apresentado em forma de aula com slides, mas sempre buscando a troca de conhecimentos entre as alunas e os ACS.

No primeiro encontro, foi utilizada uma dinâmica na qual os ACS separaram diversas fotos que caracterizavam os marcos do desenvolvimento por idade da criança. Assim, houve maior interação entre os agentes, alunas e demais pessoas da equipe, com cada um auxiliando o outro nas dúvidas que surgiam. No final, as respostas às questóes levantadas na dinâmica foram apresentadas nos slides.

Outras dúvidas também apareceram, por exemplo, em relação ao desenvolvimento na criança nos casos de síndrome de Down, autismo e deficiência visual. Foi acordado então que essas temáticas seriam retomadas no último encontro para discussáo e esclarecimento das dúvidas.

No segundo encontro, foram apresentadas e debatidas as temáticas da cartilha relacionadas à alimentaçáo, higiene, vacinação, cuidados com a casa. Os ACS tinham amplo conhecimento sobre esses assuntos, assim o compartilhamento de informaçóes foi muito rico.

No terceiro encontro, foram discutidos os direitos da criança e sobre o Estatuto da Criança e do Adolescente (ECA). Os ACS conheciam bem o ECA e o procedimento que deveria ser feito caso alguma criança não tivesse seus direitos garantidos, apesar de relatarem a dificuldade devido ao sistema em rede do município para que de fato as crianças fossem protegidas, quando necessário. Para acrescentar, na discussão foram apresentados os conceitos de fatores de risco, proteção e vulnerabilidade por meio de uma referência que não estava na cartilha, mas que os ACS acharam interessante conhecer (SAPIENZA; PEDROMÔNICO, 2005).

Já no último encontro, retomamos as dúvidas geradas sobre o desenvolvimento infantil no primeiro encontro. Para isso, as respostas às dúvidas levantadas foram discutidas por meio de pesquisas em artigos e outros materiais que as alunas tinham estudado no decorrer da graduação.

O grupo de alunas recebeu devolutiva positiva dos ACS não somente sobre o período da capacitaçáo, mas também sobre o material e a metodologia utilizados, destacando a importância das reflexões e da discussão sobre as temáticas, e a utilização de artigos científicos para sanar suas dúvidas. 
Por intermédio dessa experiência, notou-se que ainda existe pouco espaço no cotidiano de trabalho dos ACS para capacitaçóes, uma vez que, como já colocado, existe uma grande demanda de trabalho.

Segundo Peduzzi et al. (2009), todos os trabalhadores de saúde precisam da atualização técnica e científica, assim como momentos de espaços de reflexão sobre suas práticas, conforme também garantido pela política pública de educação permanente nos serviços de saúde (BRASIL, 2007).

Porém, estudos demonstram a fragilidade nos serviços para a instauração de tais momentos de educação continuada, como na própria atenção básica de saúde, na qual deveriam ser incluídas mais atividades educativas contextualizadas ao seu território e população (BRASIL, 2007; PEDUZZI et al., 2009).

$\mathrm{Na}$ temática da vigilância do desenvolvimento infantil, observou-se que havia algumas lacunas de conhecimento por parte dos ACS, mostrando, assim, a importância de capacitaçôes voltadas a essa área de conhecimento, uma vez que são esses profissionais que realizam uma aproximaçáo constante com os usuários dentro de seus contextos de vida, podendo auxiliar em detecçóes mais precoces diante de atrasos de desenvolvimento e promoção de saúde.

Conforme Andrade e Ferreira (2006), os ACS são vistos pelos usuários como os profissionais que possuem o papel mediador entre a comunidade e os profissionais de saúde da atenção básica devido ao trânsito - domicílio e unidade - e à relação de cuidado que produzem.

Dessa forma, a experiência das capacitações se mostrou um espaço para a reflexão e troca de conhecimento sobre a vigilância do desenvolvimento infantil contextualizado no cotidiano dos ACS daquela unidade, sanando dúvidas, dificuldades, mas também potencializando a troca de conhecimento já existente entre agentes e com as alunas.

\subsubsection{USF Maria Stella Fagá}

Na USF Maria Stella Fagá, a capacitação foi realizada em dois dias, com a participação de 12 ACS.

A capacitação iniciou-se com as apresentações dos participantes e, em seguida, foi realizada uma dinâmica sobre a origem do nome, objetivando maior interação entre os participantes. Então, a cartilha "Toda hora é hora de cuidar" foi apresentada.

Cabe ressaltar que os participantes da capacitação eram novos na profissão de ACS e recém-contratados. Por esse motivo foi solicitado que eles falassem um pouco sobre a rotina de trabalho e sobre o como era o contato deles com as famílias que iam até a
USF. Muitos relataram que tinham pouco contato com as famílias ainda e estavam realizando serviços internos na unidade.

A capacitação foi dividida nos dois dias, de acordo com a temática da cartilha. No primeiro dia, foram trabalhados os quatro primeiros temas com as dinâmicas de aproximação dos ACS. No segundo dia, os últimos cinco temas foram apresentados e discutidos com os participantes. De diferente modo, nessa unidade foram realizadas dinâmicas para aproximação dos ACS entre si e com as temáticas que seriam discutidas.

Foram realizadas quatro dinâmicas para trabalhar alguns temas da cartilha (rede de apoio e suporte social, marcos do desenvolvimento infantil, alimentação e diretos da criança), exemplificadas na Tabela 1, enquanto os demais temas foram trabalhados por meio de discussões e de leituras.

Nenhuma dúvida foi levantada pela equipe, que trouxe a participação em dinâmicas como ponto principal para o bom entendimento do conteúdo apresentado.

De acordo com Puschel e Ide (2007, p. 91-94), a utilização de dinâmicas são estratégias que

[...] possibilitam aos participantes que estes se sintam em um ambiente agradável, mais relaxado, capaz de favorecer a mobilizaçáo de seus conceitos e que proporcionam maior possibilidade de abertura ao novo.

Essa estratégia também se apresenta como ferramenta facilitadora do processo de ensino-aprendizagem e como um meio de trabalhar afetivamente com os participantes (PUSCHEL; IDE, 2007).

Dessa forma, foi possível observar, a partir da experiência, como as dinâmicas potencializam a interação entre os participantes, visto a possibilidade de tal interação ser mais informal, propiciando um ambiente mais confortável e também potente para discussóes e para o espaço de trocas de conhecimentos como a capacitação propóe.

As alunas tiveram de igual modo uma boa devolutiva da equipe, a qual, além do conhecimento de seus colegas de trabalho, destacou a importância de se discutir esse conteúdo entre eles para a identificação de boas práticas e ideias para a vigilância do cuidado integral à criança.

\subsection{Capacitação das famílias}

A capacitação das famílias foi trabalhosa, porém com resultados expressivos sobre as temáticas de maior importância para as mães dessas USF. Quando 
Tabela 1. Dinâmicas utilizadas durante a capacitação dos agentes comunitários de saúde e dos usuários das Unidades de Saúde da Família.

\begin{tabular}{|c|c|c|c|}
\hline Técnica & Objetivos & $\begin{array}{c}\text { Recursos } \\
\text { necessários }\end{array}$ & $\begin{array}{c}\text { Desenvolvimento da } \\
\text { atividade }\end{array}$ \\
\hline $\begin{array}{l}\text { Escolha do } \\
\text { nome. }\end{array}$ & $\begin{array}{l}\text { Acolhimento, autoconhecimento, } \\
\text { resgate da identidade, integração e } \\
\text { reflexão. }\end{array}$ & $\begin{array}{l}\text { Sala com cadeiras } \\
\text { em círculo. }\end{array}$ & $\begin{array}{l}\text { Cada participante relata a } \\
\text { história do seu nome. }\end{array}$ \\
\hline $\begin{array}{l}\text { Vídeo sobre } \\
\text { violência } \\
\text { doméstica. }\end{array}$ & $\begin{array}{l}\text { Disparador da atividade, sensibilizar } \\
\text { e estimular a reflexão sobre os } \\
\text { direitos da criança. }\end{array}$ & Notebook. & $\begin{array}{l}\text { Os participantes assistem } \\
\text { ao vídeo e realiza-se breve } \\
\text { discussão sobre ele. }\end{array}$ \\
\hline $\begin{array}{l}\text { Brincando de } \\
\text { júri. }\end{array}$ & $\begin{array}{l}\text { Obter diferentes visões sobre um } \\
\text { tema, reflexão e análise de um caso } \\
\text { sob vários olhares, conhecimento } \\
\text { dos direitos da criança, permitir a } \\
\text { sensibilização e a alteridade. }\end{array}$ & $\begin{array}{l}\text { Adequar e } \\
\text { posicionar as } \\
\text { cadeiras de acordo } \\
\text { com um cenário de } \\
\text { tribunal. }\end{array}$ & $\begin{array}{l}\text { Leitura das páginas } 88 \text { a } 97 \\
\text { do manual de apoio e } 24 \text { a } 26 \\
\text { da cartilha para fundamentar } \\
\text { a encenação. Em seguida, } \\
\text { dividem-se os personagens } \\
\text { e realiza-se a encenação. } \\
\text { Finaliza-se com a discussão da } \\
\text { dinâmica. }\end{array}$ \\
\hline $\begin{array}{l}\text { Fotos } \\
\text { cronológicas. }\end{array}$ & $\begin{array}{l}\text { Estimular o conhecimento sobre } \\
\text { o desenvolvimento infantil entre } \\
0 \text { e } 6 \text { anos, resgatar a infância } \\
\text { dos participantes, com integração } \\
\text { entre eles e discussão acerca do } \\
\text { desenvolvimento da criança. }\end{array}$ & $\begin{array}{l}\text { Fotos trazidas pelos } \\
\text { participantes. }\end{array}$ & $\begin{array}{l}\text { Divididos em grupos, } \\
\text { solicita-se que organizem } \\
\text { as fotos de acordo com as } \\
\text { faixas etárias, discutindo o } \\
\text { desenvolvimento esperado } \\
\text { para cada etapa. Em seguida, } \\
\text { realiza-se a apresentação da } \\
\text { tarefa e discute-se sobre o } \\
\text { tema. }\end{array}$ \\
\hline
\end{tabular}

dizemos trabalhosa, destacamos a importância do vínculo dos ACS com a família assistida, pois, nesse momento, eles foram o elo entre as graduandas e as famílias, ficando responsáveis por convidá-las, com o critério de ter crianças de 0 a 6 anos como membro familiar.

A formação do vínculo é uma proposta do Ministério da Saúde para o Programa de Saúde da Família, tendo como ponto central o estabelecimento de vínculos e a criação de laços de compromisso e corresponsabilidade entre os profissionais de saúde e a população. Assim, o sujeito passa a tê-lo como referência de seu tratamento, mantendo uma relação próxima a partir do conhecimento de seu trabalho (OLIVEIRA; SPIRI, 2006).

Destacamos também a diferença nos locais para as capacitações das unidades, pois a USF Jardim São Carlos preferiu encontros individuais e semanais realizados nas residências, enquanto a UBS Maria Stella Fagá optou por encontros em grupo na de sala de espera da unidade.

Participaram da capacitação na USF Jardim Sáo Carlos quatro famílias, todas elas tendo a mãe como cuidadora principal. Foi realizado um dia de encontro, com duração de aproximadamente $1 \mathrm{~h} 30$, em um dia e horário acordado entre as mães e as alunas. Na USF Maria Stella Fagá, participaram do grupo na sala de espera 15 famílias, todas com a mãe como cuidadora principal de seus filhos. Foi realizado em um encontro, com duração de $2 \mathrm{~h} 30$ aproximadamente, no dia acordado entre a equipe da unidade e as alunas. Nessa unidade, podemos destacar não somente a participação dos ACS, mas também dos demais profissionais da equipe, que se reuniram com as mães, agindo de acordo com seu nível de competência específico, contribuindo para esclarecimento de dúvidas das participantes.

Ambas as capacitaçóes tiveram as mesmas etapas. Primeiramente, foi explicado todo o processo e objetivos da atividade de extensão, deixando claro a não obrigatoriedade da participaçáo e de permanecer na capacitação.

Tanto nos encontros individuais como em grupo era realizada uma apresentação das mães, com questôes sobre elas e sua família. A Figura 1 ilustra as comparaçóes entre as unidades sobre a caracterizaçáo das participantes de acordo com suas apresentaçóes.

$\mathrm{Na}$ maioria das questóes, existia uma diferença significativa entre uma unidade e outra; apenas a faixa etária entre as participantes se aproximou, como demonstrado na Figura 1. Percebe-se, assim, que a 
individualidade de cada território se fez presente nessa etapa da atividade de extensão.

Destacamos então a individualidade como fonte das diferenças de concepção, a partir das quais os conhecimentos são construídos. Dessa maneira, foram respeitadas as características de cada unidade a fim de considerar seus saberes e vivências particulares (DELLA FONTE, 2010).

Algumas temáticas foram destacadas pelas mães: na USF Jardim Sáo Carlos, o afeto; na USF Maria Stella Fagá, os perigos em casa. Como semelhança entre as unidades, destacou-se o direito das crianças como temáticas de maior relevância. A Figura 2 ilustra a comparação entre as temáticas identificadas como de maior importância durante a capacitação para as máes por unidade.
Podemos perceber, com nossas observaçóes e a partir dos produtos que essas mães desenvolveram durante as dinâmicas, que essas temáticas estáo diretamente ligadas às relaçóes com seus filhos.

Sobre o afeto, Souza Neto e Silva (2012) traz que a proximidade do cuidador responsável com a criança funciona como uma busca pela segurança e apoio, quer seja nos momentos de adversidade ou para proporcionar uma capacidade funcional da personalidade. Bee (2003) também coloca que, mesmo a criança tendo um repertório inato de capacidades, a presença de um ambiente afetivo é primordial para a formação do vínculo e do apego. Quando as mães destacam o afeto, podemos pensar na necessidade de compartilhamento de suas inseguranças e desafios diários com outras máes, questionamentos como melhorar seu tempo com seus filhos e a melhor

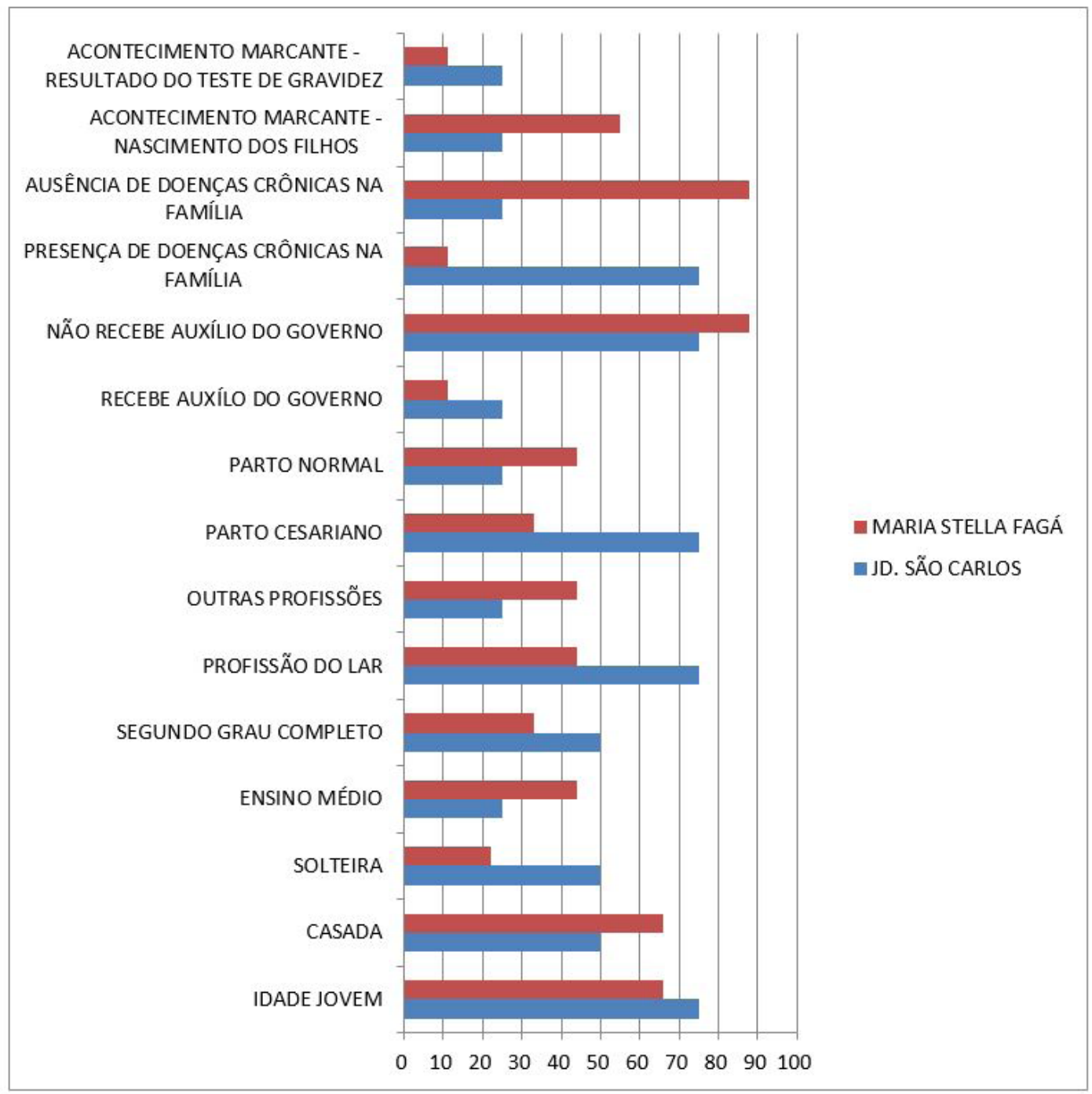

Figura 1. Caracterização dos participantes. 


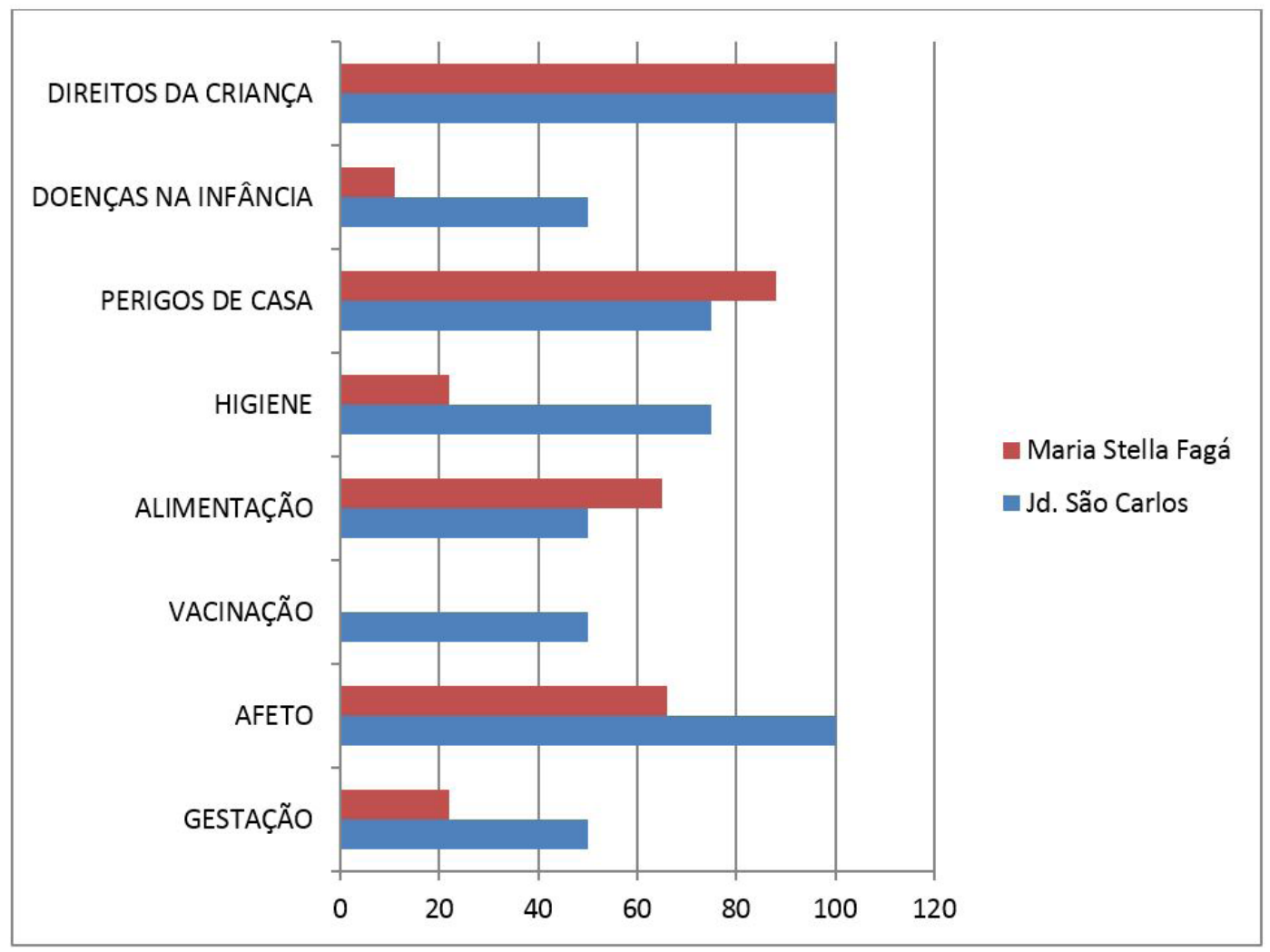

Figura 2. Comparação dos temas mais discutidos durante a capacitação.

maneira de se fazer isso. Assim, espera-se que, com a capacitação, as mães possam levar para seu dia a dia a importância de um momento com os filhos e de se dedicarem ao cuidado deles, proporcionando tempos de qualidade às crianças.

A temática de perigos em casa nos leva a uma importante reflexão. Percebeu-se que existia um conhecimento sobre os perigos em casa, mas muitas vezes não era apresentada uma ação para evitar acidentes. Levanta-se, assim, uma hipótese de que tal prática muitas vezes não é possível devido ao pouco tempo das máes para o cuidado com a casa e mesmo a identificação de onde se encontram os perigos para a criança. Observou-se com as narrativas das participantes poucas falas de açóes que tiveram diante dos perigos encontrados. Em sua maioria aparecia o que faziam após um acidente. Destaca-se então a importância dos ACS para auxiliar na identificação dos perigos domésticos e alertar as famílias por eles assistidas.

Ao estabelecer que é dever da família, da sociedade e do Estado assegurar à criança e ao adolescente, com absoluta prioridade, o direito à vida, à saúde, à alimentação, à educação, ao lazer, à profissionalização, à cultura, à dignidade, ao respeito, à liberdade e à convivência familiar e comunitária, a Constituição Federal de 1988 criou, em relação à família, ao Estado e à sociedade, a obrigação de colocá-los a salvo de toda forma de negligência, discriminação, exploração, violência, crueldade e opressão (BRASIL, 1988).

Dessa maneira, o ACS é um ator importante na instrução da família quanto aos direitos dos filhos. É na relação entre família e agente, durante as visitas domiciliares, que podem ser identificadas as necessidades de intervençóes e/ou procura por órgãos que garantam a proteção à criança.

Após a capacitação, foi realizada uma avaliação de todo o processo. As mães, em sua unanimidade, elogiaram o modo como a capacitação foi realizada, a discussão e a reflexão sobre as temáticas. Três das quatro mães que fizeram a capacitação individualmente alegaram a preferência por futuras capacitaçóes em grupo para que estas fossem mais bem aproveitadas, e as que fizeram em grupo destacaram a importância da troca de experiências entre elas e com a equipe.

Assim, levando-se em consideração as descrições de Ballarin (2003) sobre a atuação do terapeuta ocupacional em grupos, faz-se importante a presença desse profissional como possível coordenador dos grupos, responsável pela sua constituição, exercendo 
seu papel por meio da avaliação do número de participantes, da realização do encaminhamento, da escolha de critérios de seleção, do estabelecimento do contrato terapêutico, da preparação do ambiente e dos materiais.

\section{Conclusão}

Com o intuito de promover capacitaçóes e trocas de experiências a respeito da vigilância do desenvolvimento infantil e cuidado integral à criança, este trabalho utilizou a metodologia de educaçáo continuada com os ACS e famílias usuárias da USF por intermédio de um projeto de extensão.

A realização de capacitaçóes por meio de dinâmicas e de discussóes em grupo pode ser definida como açôes da educação ou formação continuada. Estas, segundo Gatti, Barreto e André (2011), consistem em realização de oficinas, palestras, seminários e cursos de curta duração, presenciais e a distância, ofertados pelas próprias Secretarias de Educação ou decorrentes de contratos firmados com instituições universitárias, institutos de pesquisa ou instituiçôes privadas. Quanto à capacitação, esta pode vir ao encontro da concepção da educaçáo continuada quando a entendemos como forma de tornar capaz e habilitar alguém para também tornar-se educador (MURBACK, 2008). Segundo esse autor, existem diferentes conceitos de educação continuada ao longo do tempo e que respondem a diferentes concepçôes e interesses. As experiências vividas nessa atividade de extensão se enquadram na formação humana de modo integral, considerando os aspectos socioeconômicos, político e cultural, pois visou provocar reflexão, ressignificação e apropriaçáo dos sujeitos envolvidos diante de conteúdos e práticas.

Outro importante resultado dessa atividade de extensão foi o fortalecimento do vínculo das alunas de graduação, que participaram da formação nas USF, bem como a identificação da importância de projetos desenvolvidos nesse cenário de atençáo básica, visando à educação continuada e ao empoderamento dos ACS.

De acordo com Oliver e Almeida (2007, p. 125):

O terapeuta ocupacional é um elemento relevante em programas que atuam diretamente na comunidade, pois por sua formação interdisciplinar poderá estimular o desenvolvimento de açóes que estejam focadas na esfera individual e na coletiva, contribuindo para o reconhecimento das necessidades da comunidade e dos indivíduos que nela residem.
Dessa forma, pensar na Terapia Ocupacional na atenção básica é pensar em uma atuação realizada diretamente no território, visando proporcionar aos indivíduos acesso de qualidade às informaçôes $\mathrm{e}$ práticas, a fim de que seja possível alcançar melhorias na qualidade de vida dos sujeitos que buscam as USF.

Em uma revisão de literatura realizada por Bassia, Malfitano e Bianchic (2012), a maioria dos trabalhos encontrados sobre a atuação da Terapia Ocupacional na atenção básica constitui-se prioritariamente por intervenções no âmbito da reabilitação e ações voltadas a pessoas com deficiência. Trabalhos voltados à promoção de saúde e ao cuidado integral à saúde da criança são novos na atuação da Terapia Ocupacional na atenção básica em saúde. Dessa maneira, destaca-se a relevância do presente estudo, ainda mais quando se associa à formação do estudante de graduação para o contexto do Sistema Único de Saúde.

Foi observado o quanto é potente intervir nesse contexto promovendo ações de vigilância do desenvolvimento infantil a partir das capacitaçóes oferecidas aos ACS. Houve feedback positivo de todos os participantes (ACS e máes), pois diversos temas foram abordados e muitas dúvidas puderam ser sanadas. Além disso, os ACS relataram a falta de capacitaçóes, visto que muitas vezes não tiveram contato com temáticas específicas, como os marcos do desenvolvimento infantil, o que dificulta a detecção e a intervenção precoce das demandas.

Ainda merece destaque a questáo do monitoramento da criança em momentos cruciais do seu desenvolvimento. De acordo com Fox e Rutter (2010), as experiências precoces têm um profundo efeito sobre o desenvolvimento humano, assim como os períodos críticos, ou as "janelas de oportunidades", durante os quais alguns tipos experiências têm efeito fundamental no desenvolvimento de habilidades e de competências. Dessa maneira, a avaliação regular do desenvolvimento infantil é fundamental para que as crianças sejam atendidas em suas necessidades de estimulação.

O monitoramento do desenvolvimento infantil pode ser implementado em programas públicos com a finalidade de vigilância do desenvolvimento. Documentos do Ministério da Saúde (BRASIL, 2002) apontam que as USF podem ser locais adequados para tal, e as equipes de profissionais de saúde da USF podem, em conjunto com as famílias, participar do processo de avaliação do desenvolvimento das crianças e inserir procedimentos simples para essa ação na rotina das USF (SIGOLO, 2011).

Assim, pensando a infância como um período importante de cuidados para um bom desenvolvimento, 
conclui-se que este relato contribui para fomentar a importância de açôes de promoção da vigilância do desenvolvimento infantil, visando ao campo da saúde primária e contando com a participação de diferentes atores, buscando promover o cuidado integral à infância.

Cabe ao processo da educaçáo continuada colocar o conhecimento como principal transformador de sujeitos, possibilitando a superação dos problemas e dificuldades existentes. Dessa forma, destaca-se a importância da aproximação da universidade com a comunidade, com o intuito de efetivar as açóes de promoçóes de saúde, a detecção de atrasos no desenvolvimento e o empoderamento dos sujeitos envolvidos nesses contextos.

\section{Referências}

ANDRADE, K. L. C.; FERREIRA, E. F. Avaliação da inserção da odontologia no Programa Saúde da Família de Pompeu (MG): a satisfação do usuário. Revista Ciência \& Saúde Coletiva, Rio de Janeiro, v. 11, n. 1, p. 123-130, 2006.

BALLARIN, M. L. G. S. Algumas reflexôes sobre grupos de atividades em Terapia Ocupacional. In: PÁDUA, E. M. M.; MAGAlHĀES, L. V. (Org.). Terapia Ocupacional: teoria e prática. Campinas: Papirus, 2003. p. 63-78.

BASSIA, B. G. C.; MALFITANO, A. P. S.; BIANCHIC, P. C. O Terapeuta Ocupacional na Atenção Básica em Saúde: a representatividade em revistas e nos congressos brasileiros da área. Cadernos de Terapia Ocupacional da UFSCar, São Carlos, v. 20, n. 3, p. 443454, 2012. Disponível em: <http://www.cadernosdeterapiaocupacional.ufscar.br/index.php/cadernos/article/ view/688>. Acesso em: 23 maio 2015.

BECK, A. R. M.; LOPES, M. H. B. M. Cuidadores de crianças com câncer: aspectos da vida afetados pela atividade de cuidador. Revista Brasileira de Enfermagem, Campinas, v. 60, n. 6, p. 670-675, 2007. Disponível em: <http://www.scielo.br/pdf/reben/v60n6/09.pdf>. Acesso em: 25 mar. 2012.

BEE, H. Juntando tudo: a criança em desenvolvimento. In: BEE, H. A criança em desenvolvimento. Sáo Paulo: Artmed, 2003. p. 503-526.

BRASIL. Fundo das Naçóes Unidas para a Infância UNICEF. Artigo 227 da Constituição Federal de 1988. Capítulo VII: da família, da criança, do adolescente, do jovem e do idoso. Diário Oficial [da] República Federativa do Brasil, Brasília, DF, 05 out. 1988.

BRASIL. Ministério de Saúde. Secretaria de Políticas Públicas de Saúde. Departamento de Atenção Básica. Saúde da criança: acompanhamento de crescimento e desenvolvimento infantil. Brasília: Ministério da Saúde, 2002.
BRASIL. Ministério da Saúde. Portaria no 1.996/GM, de 20 de agosto de 2007. Dispóe sobre as diretrizes para a implementação da política nacional de educação permanente em saúde e dá outras providências. Diário $O f$ cial [da] República Federativa do Brasil, Brasília, DF, 22 ago. 2007.

BRASIL. Ministério da Saúde. Politica Nacional da Atenção Básica. Brasília: Ministério da Saúde, 2012.

CHIESA, M. A.; BATISTA, K. B. C. O Projeto Nossas Crianças: janelas de oportunidades: possibilidades e limites para atenção à Criança. In: CHIESA, M. A.; BATISTA, K. B. C. Promoção da saúde da criança: a experiência do Projeto Nossas Crianças, janelas de oportunidades. Sáo Paulo: Escola de Enfermagem da USP, 2003. p. 16-17.

DELLA BARBA, P. C. S. et al. Formação inovadora em Terapia Ocupacional. Interface - Comunicação, Saúde, Educação, Botucatu, v. 16, n. 42, p. 829-842, 2012. Disponível em: <www.scielo.br/scielo.php?script=sci_ arttext\&pid=S1414-32832012000300019\&lng=en\&nr $\mathrm{m}=\mathrm{i}$ so>. Acesso em: 05 ago. 2015.

DELLA FONTE, S. S. Agenda pós-moderna e neopositivismo: antípodas solidários. Educação \& Sociedade, Campinas, v. 31, n. 110, p. 35-56, 2010.

FOX, N. A.; RUTTER, M. Introduction to the special section on the effects of the early experience on development. Child Development, New Jersey, v. 81, n. 1, p. 23-27, 2010.

GATTI, B. A.; BARRETO, E. S. S.; ANDRÉ, M. E. D. A. Politicas docentes no Brasil: um estado da arte. Brasília: UNESCO, 2011. Disponível em: <http:// www.scielo.br/scielo.php?script $=$ sci_arttext\&pid $=$ S0100-15742012000100021>. Acesso em: 05 ago. 2015.

GODOY, A. S. Introdução à pesquisa qualitativa e suas possibilidades. Revista de Administração de Empresas, São Paulo, v. 35, n. 2, p. 57-63, 1995.

LORDELO, E. R.; FONSECA, A. L.; DE ARAUJO, M. L. V. B. Responsividade do ambiente de desenvolvimento: crenças e práticas como sistema cultural de criação de filhos. Psicologia, Reflexão e Critica, Porto Alegre, v. 13, n. 1, p. 73-80, 2000. Disponível em: <http://www. scielo.br/scielo.php?script=sci_arttext\&pid=S0102$-79722000000100009 \& \operatorname{lng}=p t \& n r m=i s o \& t \operatorname{lng}=p t>$. Acesso em: 12 abr. 2012.

MURBACK, S. E. S. L. Educação continuada em saúde coletiva: desafios e possibilidades. 2008. 20 f. Dissertação (Mestrado em Educação) - Universidade Estadual de Campinas, Campinas, 2008.

OLIVEIRA, E. M.; SPIRI, W. C. Programa Saúde da Família: a experiência de equipe multiprofissional. Revista de Saúde Pública, São Paulo, v. 40, n. 4, p. 727-733, 2006.

OLIVER, F. C.; ALMEIDA, M. C. Reabilitaçâo baseada na comunidade. In: CAVALCANTI, A.; GALVÃO, 
C. Terapia Ocupacional: fundamentação e prática. Rio de Janeiro: Guanabara Koogan, 2007. p. 125-130.

PEDUZZI, M. et al. Educational activities for primary healthcare workers: permanent education and inservice healthcare education concepts in the daily life of primary healthcare units in São Paulo. Interface - Comunicação, Saúde, Educação, Botucatu, v. 13, n. 30, p. 121-134, 2009.

PEREIRA, M. P. B. O território no Programa de Saúde da Família. Revista Brasileira de Geografia Médica e da Saúde, Uberlândia, v. 2 n. 2, p. 47-55, 2006.

PUSCHEL, V. A. A.; IDE, C. A. C. A capacitação de enfermeiros para a assistência domiciliar: uma abordagem psicossocial. Acta Paulista de Enfermagem, São Paulo, v. 20, n. 1, p. 91-94, 2007.

SAPIENZA, G.; PEDROMÔNICO, M. R. M. Risco, proteção e resiliência no desenvolvimento da criança e do adolescente. Psicologia em Estudo, Maringá, v. 10, n. 2, p. 209-216, 2005.

SIGOLO, S. R. R. L. Avaliação do desenvolvimento infantil em programas de saúde da família. $195 \mathrm{f}$. Disser- tação (Mestrado em Educação Especial) - Universidade Federal de São Carlos, São Carlos, 2011.

SOUZA NETO, Z. G. S.; SILVA, M. R. C. Perspectiva psicanalitica do vínculo afetivo: o cuidador na relação com a criança em situação de acolhimento. Porto Velho: Instituto Luterano de Ensino Superior de Porto Velho, 2012. Disponível em: <http://www.mppe.mp.br/mppe/ index.php/institucional/caops/caop-defesa-da-infancia-e-juventude/material-apoio-caop-infancia-juventude/ category/172-area-protetiva?download=348: perspecti va-psicanalitica-do-vinculo-afetivo $>$. Acesso em: $15 \mathrm{fev}$. 2015.

UNIVERSIDADE FEDERAL DE SÃO CARLOS UFSCar. Projeto pedagógico do Curso de Terapia Ocupacional. São Carlos, 2008. Disponível em: <http:// www.dto.ufscar.br/projeto-pedagogico-to>. Acesso em: 20 ago. 2015.

UNIVERSIDADE FEDERAL DE SÃO CARLOS UFSCar. Pró-reitoria de extensão (PROEX) da UFSCar. São Carlos, 2010. Disponível em: <http://www.proex. ufscar.br/site/arqs_menu_coex/apresentacoes/apresentacoes-2012/apres_coex25out-relatgestao2008-2012.pdf/ at_download/file>. Acesso em: 07 fev. 2015.

\section{Contribuição dos Autores}

Patrícia foi responsável pela orientação do trabalho e revisão do texto. Vanessa foi responsável pela organização de fontes, análises e redação do texto. Érika, Aline, Bárbara e Evellin foram responsáveis pela redação do texto. Todos os autores aprovaram a versão final do texto.

\section{Fonte de Financiamento}

Pró-Reitoria de Extensão PROEX-UFSCar. 